\title{
Overview of Hematopoietic Stem Cells in Systemic Cancer Treatment, Aging, Pregnancy, and Radiation Hormesis
}

\author{
Aleksei N. Shoutko \\ Laboratory for Improvement of the Cancer Treatment Methods, A.M. Granov Russian Research Center for Radiology and Surgical \\ Technologies, Ministry of Health Care of the Russian Federation, Saint-Petersburg, Russia \\ Email:shoutko@inbox.ru
}

How to cite this paper: Shoutko, A.N. (2019) Overview of Hematopoietic Stem Cells in Systemic Cancer Treatment, Aging, Pregnancy, and Radiation Hormesis. Advances in Molecular Imaging, 9, 19-42. https://doi.org/10.4236/ami.2019.92003

Received: March 18, 2019

Accepted: April 25, 2019

Published: April 28, 2019

Copyright $\odot 2019$ by author(s) and Scientific Research Publishing Inc. This work is licensed under the Creative Commons Attribution International License (CC BY 4.0).

http://creativecommons.org/licenses/by/4.0/

\begin{abstract}
Background: The unavoidable links between the benefits of conventional systemic treatment of cancer and the side effects such as lymphopenia. Objective: To analyze this phenomenon in view of the newly discovered trophic function of circulating hematopoietic stem cells (HSC) and their lymphocyte descendants. Method: We used population statistics and recent current research involving natural aging and preliminary aging with cancer, its cytotoxic therapy, eclampsia at pregnancy, and radiation hormesis. Results: In contrast to immune-defense interpretations of these health conditions, the trophic influence of HSC and morphogenic lymphocytes on natural tissue renewal and regeneration after sublethal injuries eliminates the majority of covered inconsistencies, which are inherent to the dominating idea of cellular immunity. Conclusion: Our examination led to the feeding influence of lymphopoiesis on tumor progression, an indirect mechanism of tumor growth control by systemic therapy via either destruction of trophic cells, or by competitive distraction from malignant tissue via reparation of sublethal injuries in normal tissues. Analyses also involved similarities of the mechanisms of systemic chemotherapy and total body/half body radiotherapy in low doses, as well as the futility of the theoretical opposition of the radiation hormesis phenomenon to the linear non-threshold model, dominant in radiobiology.
\end{abstract}

\section{Keywords}

Circulating Hematopoietic Stem Cells, Trophic Lymphocytes, Distant Cancer Treatment, Ageing, Eclampsia, Hormesis

\section{Introduction}

The concept that the immune system can recognize and eliminate primary de- 
veloping tumors has existed for nearly 100 years. The idea of a fight of the body with neoplasm, which has been once presented with an enthusiastic approval, turned out little by little to be nothing more but acceptance of the wish for the reality, optimistic self-deception. However, it does not lead to an open public discussion. Most of the scientists still believe that here will be a day, when a research genius releases the resistance forces of a body, and they destroy forever a mortal enemy of the humanity. This belief becomes stronger in spite of obvious truisms, such as invariable difficulties in solving two opposite problems, a successful rejection of cancer tissue on one hand, and successful prevention of rejection of heterologous transplants of normal tissue on the other hand, despite declared theoretical progress in cellular immunity, where these two tasks are considered. A "favorite" site of the tumor spread/dissemination in the body is lymph nodes, which are the very place of "protective" lymphocytes; an immutable lymphotoxicity of anti-cancer therapy regardless of a long history of its constant improvement; procedures, which reduce the somatic toxicity of chemo, decrease their anti-cancer activity, and so on.

Protumor activity of circulating cells originating from the bone marrow (BM) is the main strategic challenge to the dominant doctrine of cellular immunity. The generation of a protumor angiogenic microenvironment [1] is no more than part of the recently discovered morphogenic (trophic, feeding, morphogenic) function (MF) for circulating hemopoietic stem cells (HSC) and their lymphoid descendants, recruited in different organs and tissues from the BM [2]-[10]. Morphogenic migratory cells (MC) include the ancestral and angiogenic CD133+HSC, progenitor CD34+HSC, and young emigrating cells from the BM and thymus like the terminal deoxynucleotidyl transferase-positive ( $\mathrm{TdT}+$ ) prelymphocytes, descendant $\mathrm{CD} 31+$ angiogenic $\mathrm{T}$-lymphocytes, and other "regulatory" cells [2] [8] [11] [12] [13] [14]. These MC may become committed to their own tissues with different histotypes [5] [15] [16] [17], and their abilities to potentiate regeneration, reparation, and cell renewal in target organs compromise the use of lymphocytes against tumors as a "foreign invader". Thus, MF opens up an opportunity for new explanations of numerous viability phenomena in the fields of aging, pregnancy, malignancy, cancer treatment, radiobiology, and transplantology. All these situations are associated with systemic chronic inflammation (SCI), which is characterized by two opposite processes involving neutrophilia (N) and lymphopenia (L). The increasing N/L ratio (NLR) correlates with the severity of the clinical outcomes of many diseases [18] [19]. Besides lymphopenia, the SCI is also associated with myelosuppression, body weight deficits, frailty, and higher risk of death. All signs of SCI involve a single complex, and differ only in the degree of their severity, which corresponds to clinical situations.

Here, we apply MFs to some prominent truisms in the field of human viability, and propose alternative interpretations for some of them, based on the function of the critical physiological system, but not at the level of its separate com- 
ponents such as molecules, genes, or cells, which cannot be responsible for the viability of organisms at large. Lymphopoiesis is a vulnerable system in mammals, and lymphopoietic reproductive capacity is the most amortizable among other physiological tissue systems in the thymus, BM, gastrointestinal tract, breast, ovary, skin, lung, kidney, liver, adrenal, adipose tissue, muscle, bone, and brain, which could all be responsible for the natural involution of the organism [20].

\section{Considered Threats to Viability}

\subsection{Aging}

The theory of immunology states that aging arises from dysregulation of the immune response to foreign antigens and is associated with acceleration of inflammation followed by natural frailty at the end of life [21] [22], and during different somatic diseases including cancer [23]. However, a dramatic decline in T-lymphopoiesis of the old people is primarily dependent on the status of progenitor niches in the BM and thymus [24], which, in turn, become depleted at 40 years of age, with either $100 \%$ for the thymus or BM in the lower legs and femurs, or $30 \%-75 \%$ for the BM in bones, sternum, and ribs [25]. The absolute number of circulating CD133+ and CD34+ cells and their clonogenic capacities progressively and significantly decrease with advancing age [26] [27]. Natural exhaustion of lymphopoiesis is responsible for the frailty syndrome and the real senility/aging of the naturally frail population of those $\geq 75$ years of age [28] [29]. NLR positively correlates with aging in the healthy population [30], and the ratio increases sufficiently during multiple organ dysfunction syndrome (MODS) [31] [32] due to deadly lymphopenia (lower than $0.5 \times 10^{9} / \mathrm{L}$ ) with concomitant reduced innate $\gamma-\delta$ T cells, which are able to migrate to different epithelial tissues [33].

Analysis of natural survival curves by age for countries with high social status has shown specific rectangularity of the curve, which arises due to the strongly increasing exponential rate of death (ERD) at the end of life. The younger population ( 25 - 75 years of age) in the US, Sweden, and UK die slowly, with an ERD $\approx$ $0.0023-0.0028$ per year. ERD in the last $20-25$ years of life for the US population involves an $\mathrm{ERD} \approx 0.0812$ per year [34], for Sweden it involves $\approx 0.102$ per year [35], and for the UK it involves $\approx 0.146$ per year [36]. Such large values of ERD indicate that most of the oldest population $(88 \%-97 \%)$ has died in the last 25 years of life. A natural exhaustion of lymphopoiesis and an obvious deficit of trophic cells are more explainable for both MODS and life-threatening multiple organ failures, which also develop during natural frailty, due to poisoning/toxicity, burns, eclampsia, major trauma, and sepsis. The explanation of MODS by natural exhaustion of lymphopoiesis and deadly reduction of support of cellular renewal in different tissues by circulating HSC and their lymphoid descendants is very reliable. Nevertheless, the traditional explanation of MODS avoids the insufficiency of lymphopoiesis, emphasizing only inflammation with 
leukocytosis and neutrophilia [31].

\subsection{Eclampsia}

Rapid growth of the fetus during pregnancy, though natural, is associated with complications in $7 \%$ of cases, involving preeclampsia with chronic inflammation and with a high risk of death of the mother and the fetus [37] [38] [39] [40]. An eclampsia at pregnancy, leading to MODS, is consistent with the main role of temporal exhaustion of lymphopoiesis. During normal pregnancy, CD34+ VEGFR-2+ and CD133+ VEGFR-2+ angiogenic stem cells increase by the second and into the third trimester, when the mass of the growing fetus is $\geq 500$ g. This excess of circulating HSC declines to nulligravida (a woman who has never been pregnant) levels by $48 \mathrm{~h}$ postpartum (the period following childbirth). During pre-eclampsia, these cells are comparatively reduced in numbers [39] and this reduction is accompanied by $10 \%-15 \%$ of maternal deaths, partially of cardiovascular origin [41] [42]. Remarkably, cardiovascular disease is the leading cause (rank 1 ) of natural death in the advanced age group ( $\geq 85$ years of age) with a high EDR [43]. Thus, an excessive rate of natural proliferation of embryonic fetal tissues can induce a reversible deficit of trophic cells in a small percentage of only those women who, probably at birth, had the lowest value of hematopoiesis that was naturally distributed in the population [44]. These data indirectly show the similarity of the temporary status of pregnancy during the originally weakest hemopoiesis with those who experience frailty during natural aging.

\subsection{Malignancy}

A cancer, being embryonic-like tissue, involves a set of conventional cellular processes used to grow the embryo during morphogenesis [45], as well as to increase the body mass intensively during a young age. In contrast to pregnancy, a malignant growth is an uninterrupted process, which efficiently leads to inflammation, frailty [28], chronic irreversible lymphopenia, anemia, protein depletion, reduced food intake, fatigue, cachexia, and death [46] [47] [48]. A high number of $\mathrm{CD} 3+$ tumor-infiltrating lymphocytes have been widely interpreted as proof of an immune defense against cancer, because they are associated with a favorable prognosis. However, the more lymphocyte infiltration there is, the higher the rate of tumor growth, and the smaller the tumor size and lower stage [49] [50] [51] [52]. This is evidence in favor of a trophic/morphogenic/proliferogenic function of migrating lymphocytes during tumor "vertical" growth, partially involving intertumoral CD34+HSC [6], which, in turn, shows a positive correlation with the microvascular density of the tumor, involving many intertumoral CD3+ lymphocytes (TILs) and FOXP3+T-regulatory lymphocytes [8] [53] [54]. The inflammation-associated infiltrates in cancer tissues serve as a niche for tumor progenitor cells, promote cancerogenesis, and may lead to recurrence of the disease after surgery [9] [55] [56] [57]. Thus, excessive consumption of feeding 
cells by rapidly growing cancer tissue or fetal tissue can induce an irreversible or reversible deficit of their reproduction in the bone marrow. Such deficits, in turn, may become fatal for longevity, independent of the nature of the excessive growth (Shoutko A, Akushevich I, Ekimova L, Karamullin M, Yashin A. The terminal exhaustion of hematopoietic potentiality as the universal cause of death. In: abstracts of the 38 th annual meeting of the European radiation research society, 2010 Sept 5 - 9; Stockholm University, Sweden 2010; p. 187). However, attempts to interpret the immune destination of tumor-infiltrating lymphocytes is continuing, but ignore the nonequivalence of the compared groups in terms of tumor size [58].

\subsection{Cancer Therapy}

In 1942 founders of chemotherapy Goodman and Gilman hypothesized that nitrogen mustard (called "synthetic lymphocidal chemical") could destroy sensitive normal white blood cells and cancerous ones [59]. At present nitrogen mustards are cytotoxic (alkylating) chemotherapy agents derived from "mustard gas", which was used as chemical warfare agents (iprite) during the First World War. According to modern sources, $85 \%$ - $90 \%$ of anticancer drugs are mielodepressants [60] [61], carcinogens [62], or act as radiomimetics [63]. Radiation and chemical genotoxic anticancer agents act on DNA, mitosis, and at metabolic checkpoints to block DNA replication. Many mechanisms like single and double strand breaks, DNA adducts, base oxidation, base deamination, DNA-protein crosslinks, and DNA-crosslinks are common [64]. Chemotherapy is known to be a greater risk factor than radiation therapy for tumorigenicity, genotoxicity, cytostaticity, mutagenicity, clastogenicity, and teratogenecity [62] [65]. Systemic (nonselective) cytotoxic cancer treatment is accompanied by side effects on healthy tissues, especially in fast-growing tissues involving inflammation, deep irreversible lymphopenia, immune suppression, anemia, bleeding or clotting, bowel dysfunction, nausea, dietary issues, hair change, infertility, heart damage, lung dysfunction, bone density loss, distress, pain, memory and other mental deficits, fatigue, weight changes, increases in the NLR [65] [66] [67] [68] [69], and cancer [62] [64] [70]. Even conventional doses of all types of anticancer drugs increase lymphopenia, myelosuppression, and hematological toxicity [61] [71], especially in older patients, because their bone marrow reserve decreases with age [72] [73] [74] [75]. Therapy usually continues until the end of life, with short breaks involving periods of remission [76] [77]. In an advanced cancer population of diverse tumor types, there is a significant decrease in progression-free survival in systemic therapy involving treatment 1 through treatment 5 , manifested as progressive exhaustion of the lymphopoietic resource and concomitant occurrence of incurability [78]. Regularity and validity of lymphopenia during a successful treatment [79] excludes it from the category of an accidental complication. During the last 5 years of life, increased reproductive activity of HSC and increased numbers of CD34+ and CD133+ cells in the circulation of 
treated patients have been shown to undergo a rapid decrease [80]. However, a satisfactory 5-year survival is present in cancer patients, when their specific reproductive activity of stem cells (ratio G2-M/CD133+cells) before treatment is excessive (for instance, five-fold greater compared with a healthy level). The short-living patients originally have a reduced number of progenitor cells, accompanied by reduced reproductive potency [80] [81] [82]. These symptoms of exhaustion manifest as a decrease in the feeding function of lymphopoiesis, and are typical for the final and ineffective period of therapy. In the last year of life, a weakened subnormal reproduction of CD34+HSC in the BM occurs, which is usually classified as a turbulent and symmetric type of cell division [83]. Thus, the benefit of treatment can arise from temporal suppression of trophic cell production, if their generation before therapy is fully sufficient. If it is not, the conventional anticancer treatment may bring about a poorer result compared with palliative therapy or even the absence of treatment [84] [85] [86] [87]. Actually, "rushed approvals of chemo result in a poor deal for both patients and cancer research" [88].

The above results showed that the inhibition of lymphocytopoiesis, regardless of physiological aging, eclampsia at pregnancy, malignant growth itself, or during treatment with cytotoxic agents, including anticancer drugs and radiation, is accompanied by a deceleration of the fast growth processes in any kind of tissue, including both normal and malignant tissues. Both cancer and cytotoxic therapy then gradually potentiate lymphocytopenia, which lasts until the death of the patient [76] [77] [78].

\section{The Potentiation of Lymphocytopenia by Both Cancer and Cytotoxic Therapy}

Most cancer patients die, losing several decades of their naturally expected life span, despite conventional therapy.

The calculated ERD of all 1.526 million cancer patients diagnosed between 2012 - 2016 in the UK for all stages and treated during a 5-year period was 0.143 per year \pm 0.004 at a confidence interval (CI) of 95\% [89]. The average ERD, calculated in the same manner for all cancer sites of the US population was 0.081 in 2014 [90]. Both calculated ERD values are comparable with average ERDs for natural aging in these two countries (see 2.1 Aging). Thus, 87\% - 97\% of cancer patients with a large ERD usually live no longer than 25 years, and die like normal senile patients.

The average ERDs calculated for the 5-year net survival of 29 cancer sites in the UK for subgroups with ages 15 - 44, 45 - 54, 55 - 64, 65 - 74, and 75 - 99 years at diagnoses showed ranges of $0.086-0.074,0.102-0.092,0.109-0.096$, $0.143-0.131$, and $0.216-0.194$ per year, respectively [89]. In a similar manner, the ERD values were calculated for all US patients dying from cancer within 5 years with ages of $<45,45-54,55-64,65-74$, and $\geq 75$ years at diagnoses, with ERDs of $0.038,0.059,0.071,0.08$, and 0.137 per year, respectively, as of 2008 - 
2014 [90]. Being joined together, both ranges can be described by the second-degree polynomial Equation 1:

$$
y=0.0000005 x^{2}-0.0036 x+0.132 ; R=0.86 \pm 0.18 ; p=0.002
$$

where the $x$-average age at diagnosis in the subgroups is in years, the $y$-averaged ERD in the subgroups is in years ${ }^{-1}$, with an $R$-correlation coefficient, and the $p$-values indicating its validity.

According to Equation (1), the ERD values slowly increase with age $(+30 \%)$ from 30 to 65 years of age, and then the rate quickly doubles from 65 to $\geq 87$ years of age, which reflects the real influence of aging. The influence of cancer progression manifests as the highest ERD value of 0.205 per year \pm 0.019 with a 95\% confidence interval of 231,126 patients with stage 3 only for different cancers from the same UK database [89]. The value of 0.205 is independent from the age at diagnosis, and the average ERD of 0.146 per year is typical for natural senescence of the UK population. Thus, the majority of treated patients with malignant diseases were older patients at the age of diagnoses. Although their lifespan was increased by 5 - 10 years because of therapy, when diagnosed between 15 - 65 years of age, it will result in the loss of 5 - 55 years of active natural longevity.

These rough calculations explain why such modest criteria as a 5-year survival rate are widely used in practice, independently of the age at diagnosis and the type of cancer. The calculations also show that a preliminary aging of patients is a result not only of malignant progression but also of conventional therapy, which promotes frailty and senescence of patients in parallel with the progress of malignant diseases. In general, modern anticancer agents for systemic therapy retain the toxic properties of their pharmacological predecessors, such as those of mustard poison. Even the results of modern immune checkpoint inhibitors (ICI) are subject to current systemic conditions, because higher NLR is associated with poorer outcomes for patients receiving ICI across studies [91] [92] [93]. ICI treatment is able to destroy the CD34+HSCs, which have PD-1 and PD-2 ligands [94]. ICI treatment depletes the common number of lymphocytes and the T-reg cells number [95] [96] [97] [98]. Furthermore, this type of therapy is also often associated with subtle, potentially fatal adverse events [99].

\section{The Proof for an Indirect Destructive Mechanism of Conventional Systemic Cytotoxic Therapy at the Level of Lymphopoiesis}

The well-known increase in malignancy by age is reversed in the oldest cohort of patients. The incidence, mortality, and prevalence of a wide variety of cancer sites $(n=24)$ stop their increases at approximately 80 years of age, and then decline during the last 25 years to a natural age limit of 105 years. [100]. During aging, the mean rank of death from infectious influenza and pneumonia (J09-J18) increases from 11 (at ages of 45 - 79 years) to 7 (at ages of 85 to $\geq 100$ years), manifesting as weakening of the immune system. However, the rank of 
death from malignant neoplasms (C00-C97) diminishes from 1 to 3 [101], reflecting their trophic dependence on lymphopoiesis. These population-based results correlate with age-dependent impairment of angiogenesis and cancer tumor growth in humans [102] [103], and are consistent with in-phase changes of the presence of the CD133 marker in blood and in the process progress of malignancy [104]. As age advances, a dramatic decline in the production of naive $\mathrm{T}$ cells has been reported [105]. In contrast to weakening of the lymphoid lineage, myeloid compartmentalization is expanded with aging, providing a proinflammatory environment in the body and becoming detrimental later in life [106]. Such age-related reduction of cancer activity cannot be explained by the widely accepted explanation that the, "immune system, which fights an infinite number of foreign antigens and breaks down with aging, impairs the body's ability to resist these invaders" [23]. The loss of malignant activity in a naturally sick population relates more realistically to a weakening of the trophic supply, which is common for normal and malignant tissues of a host. Comparison of the impact of the natural evolution of the thymus, a source of trophic young lymphocytes, on the viability of patients with nonmalignant and malignant diseases has shown a trophic contribution of the thymus toward tumor development, and assumes that use of cytotoxic therapy can exert indirect benefits via artificial lymphopenia. The increase of infectious diseases testifies to the weakening of immunity in parallel with weakening of malignant activity [107]. Lymphocytopenia can therefore contribute to the cytotoxicity of cancer [81] [108] [109] [110], slowing the growth and temporarily delaying death, at least for 5 years, and less often for 10 years. It is therefore more reliable to explain ecological data [100] [101] in terms of the exhaustion, like aging, of universal morphogenic activities of feeding lymphoid HSCs and their morphogenic descendants in cancer patients [111] [112] [113] [114]. The BM, as a resource for multiple stem cell populations, is limited, and its potency is progressively exhausted by an abnormally high consumption of trophic cells by quasi-embryonic tumors, ceasing trophic passes with the BM. A history of extra consumption of circulating feeding cells for tumor growth before diagnosis is unknown. So, previous weakening of the tropic relation in the "BM-Tumor" limits the opportunity to suppress this mechanism by periodic cytotoxic courses, and predetermines the rate of gradually developing "resistance to therapy" during the clinical period [115]. As a result, initially effective cytotoxic therapy is steadily disabled and even dangerous at later times [80] [84] [86]. A treatment usually continues until it has a chance to work but, in parallel, it exhausts lymphopoiesis from cycle to cycle, losing its effectiveness and inducing serious complications, including incurability and a higher risk of death. Intense chemotherapy can actually shorten the life of patients. People who are much older and have exhausted lymphopoiesis may not be able to tolerate intense treatment, which brings no benefit, despite its intensification [116].

Thus, the acceleration of aging and frailty by artificial suppression of lymphopoiesis in cancer patients leads to temporary restriction of malignant growth, 
in manner similar to that of natural aging. Systemic cytotoxic treatment, reproducing the phenomenon of natural senility, may destroy lymphopoiesis, rather than "stimulating the immune defense against cancer" at any age. In addition, the deadly "therapeutic" waste of sensitive stem and progenitor cells in the BM decreases its proliferogenic influence on malignant and normal tissues [117], which explains why the therapeutic benefit of cytotoxic agents is inevitably associated with "moderate" lymphocytopenia [79].

\section{Systemic Therapy Does Not Directly Control the Tumor}

The benefit of chemotherapy has been assumed to involve direct lethal activity of the drugs toward tumor cells. However, direct control of tumor growth using local irradiation can be achieved by using only a few dozen Gray (Gy) [118]. Systemic chemotherapy as well as systemic radiotherapy in such huge dose-equivalents would result in the complete ablation of the bone marrow and death of patients.

It is accepted that systemic chemotherapy cannot be lethal for people without cancer as well as nonlethal dose of total body irradiation of a healthy man is not more, than 2 - 3 Gy. Then, systemic chemotherapy is unable to kill a tumor cells fundamentally. Moreover, many authors argue that chemotherapy stimulate both the innate and adaptive arms of the immune system [119]. Tumor response to therapy is regulated by its vasculature in range of absorbed doses of radiation not less, than 10 - 20 Gy [120] [121]. Thus, nonlethal chemotherapy is not enough to control directly even most sensitive vascular structure of a tumor. The cytotoxic chemotherapy combined with administration of anti-VEGF drugs leads to improvements of survival of patients with colorectal cancer, breast cancer and non-small lung cell cancer compared to chemotherapy alone [122]. In contrast, the results generate some confusion. It is known that the efficacy of chemotherapy depends on efficient delivery of cytotoxic agents to tumor cells through efficient blood flow, whilst antiangiogenic therapy, according to the theory, should destroy blood vessels and thus prevent drug delivery. The confusion eliminates easily, as recruited in tumor microenvironment (TME) mononuclear cells have paradoxical protumor functions. They originate from BM and found in invasive tumor margins and in draining lymphoid organs or lymphoid structures adjacent to TME. TME includes HSC, protumor Treg lymphocytes and $\mathrm{B}$ lymphocytes, which convert $\mathrm{T}$ into Treg, endothelial cells and pericytes, which promote lymphangiogenesis and cancer progression, including metastases [123]. Inducible "therapeutic" lymphopenia restricts all these protumor activities indirect way. In 1981 we showed, that low-dose irradiation of whole body of tumor-bearing animals except the small shielded area of graft, retards significantly tumor growth and prolongers the life [2].

The main side effect of conventional systemic chemotherapy or systemic totalor half-body irradiation (TBI or HBI) with repeated low-dose (0.5 Gy every 4 days, total dose 2 Gy [124]; 3 Gy every 3 days, total dose 9 Gy [125]) is deep (2 - 
5-fold) lymphocytopenia. Lymphocytopoietic tissues are most vulnerable in the organism to any toxic agents, and their involution is associated with the early onset and acceleration of aging in mammals including humans [24] [75]. The allowable oncological dose of a "moderate" level of $0.5-0.8 \times 10^{9}$ lymphocytes/L [79] corresponds to acute radiation syndrome (ARS) for healthy people exposed to a single dose of ionizing irradiation of only 2 - $4 \mathrm{~Gy}$, followed by precipitously decreasing the total hematopoietic output and probability of death from $5 \%$ to 50\% [126] [127]. Clinically significant ARS after single TBI in doses as low as 2 Gy classically includes not only hematological but also gastrointestinal, cutaneous, and cardiovascular/central nervous system problems [128], i.e., the so-called MODS [31] [32]. The post-irradiation MODS is very similar to "complications" after systemic therapy [81] [129] [130]. Nevertheless, the majority of experts insist on "stimulation of anticancer immunity" when treating patients. Thus, they ignore the specific strong deficit of common lymphoid progenitors (CLP) Lin-CD34+CD38+CD127+ [131] in the BM after ageing [132] and conventional systemic therapy [133], with an obvious dependence on tumor and metastases progression from the number of intertumoral CD34+HSC [6], involving a correlation between the microvascular density with the number of intertumoral CD3+, CD3+FOXP3+regs lymphocytes [8] [53].

These data are not compatible with immune explanations, which describe "specific rearrangements on dying tumor cells, which render them visible to the immune system," involving either "replenishment of immune cell pools through its transient lymphodepletion," "subverting tumor-induced immunosuppressive mechanisms," or "exerting direct or indirect stimulatory effects on immune effectors" [134] [135] [136]. A more natural and less controversial suggestion is that the temporal benefit from cytotoxic agents is due to destroying the number of sensitive trophic HSCs and "regulatory" cells. Depending on the treatment agent dose, these trophic cells can not only be destroyed but also distracted from growing cancer cells, resulting from reparation/regeneration of numerous forms of sublethal damage to cells in other normal tissues, in systemically-treated organisms. We call such trophic redistribution a "competitive mechanism" [117].

\section{The Proof for an Indirect and "Competitive" Mechanism}

Even if a cytotoxic factor is insufficient when it comes to diminishing the number of trophic cells, there remains the possibility of distracting them from the growing tumor due to restoring the majority of sublethal injuries of normal cells in exposed neighboring tissues. The phenomenon of radiation hormesis demonstrates this possibility.

Cancer risk is lower in geographic regions with an abnormally high radiation background, which is associated with stimulation of anticancer immune defense by radiation and, hence, with the harmlessness of exposures to low doses [137] [138] [139] [140] [141]. According to this logic, hormesis is supposed to be the missing link to a better cancer treatment [142]. Moreover, "stimulation of im- 
munity" is the main argument of these authors, who base their theory on the "hormetic" or "threshold" models [143] [144] [145] [146], to attack officially recognized and dominant radiobiology arguments using the linear no-threshold model (LNT) [147] [148] [149]. The LNT model assumes that radiation damage is directly proportional ("linear") to the doses at all ranges with no safety threshold, so the term "stimulation" contradicts the idea of the total harmfulness of radiation, and is a key part of the current theoretical controversy.

However, hormesis could be explained without supposing any stimulation. Circulating trophic cells take part in tissue reparation and regeneration during adaptive response to low dose cytotoxic stress, which involves enhancement of DNA repair [150]. A lower cancer risk and concomitant increasing life span during hormesis may result from distraction of circulating trophic hemopoietic stem cells from the growing tumor to the reparation of numerous forms of sublethal radiation damage to cells in other tissues of the exposed body. Radiation as well as cytotoxic drugs both cause similar forms of DNA damage, which are single causes for cell cycle arrest and/or cell death, independently of the nature of the tissue. Approximately $80 \%$ of most representative single strand breaks of DNA and $25 \%$ - $75 \%$ of double strand breaks may be restored by the organism [64] [151] [152].

The changes in an average life span (LS) were compared in a group of whole-life irradiated dogs (a dose $3 \mathrm{mGy} /$ day of Co $60 \gamma$-rays); the weakest animals in the group died first because they were originally more sensitive to irradiation. At the same time, only the weakest animals kept a constant LS after a cumulative dose of $1100 \mathrm{mGy}$ (2700 days vs. the control of 2700 days), while healthier animals (the control of 4300 days), had after irradiation at the same dose a shorter LS of 4050 days [153]. The same cohorts of control and irradiated dogs [data extracted from the $\gamma$-Beagle Dog Tissue Archive, hosted by the Woloschak Laboratory (Chicago, IL, USA)] were divided into four subgroups with short and long mean LSs (two control and two irradiated) [154], and for each of them the sums of personal LSs were calculated. Comparison of data from the control and irradiated dogs revealed a significantly higher sum of LSs only in the exposed short-living subgroup (integral dog-years by age $=75.5$ vs. the control of 65.2). Among long-lived animals, there was no radiation hormesis (dog-years integral by age $=77.0$ vs. the control of 77.2). In contrast with long-lived animals, hormesis in the short-lived group was accompanied by an increasing percentage of animals with tissue atrophy (2.4-fold), body weight loss (2.4-fold), and significant reductions in the percentage of anemias and hemoblastoses (10-fold). There were no significant differences with controls in both exposed subgroups in terms of the incidence of solid malignancies, metaplasia, inflammation, diarrhea, and vomiting. These data confirmed the tendency of hormesis only in the weakest animals [155]. Because the frailty syndrome correlated with the loss of general somatic health and the loss of body weight [156], the data exclude the notion that radiation was associated with healing or stimulation and, 
instead, indicate that certain pathologies (e.g., hemoblastoses with high risk of quick death) may have only substituted for other nonfatal somatic problems in weaker animals [147] [154] [155]. It correlated with the typical "side effects" of conventional cytotoxic chemotherapy, which include body weight loss and immunosuppression, and was inseparable from the benefits afforded by any cytotoxic anti-malignancy treatment [79] [81] [110] [115] [125]. Hormesis, found after a dose $3 \mathrm{mGy} /$ day in the short-lived subgroup only, with greater body weight loss and tissue atrophy, suggested that the sublethal tissue injuries were adequate to the lymphopoietic potential weakened originally. If this is correct, the same radiation-induced injures in the long-lived (healthier) subgroup could be suboptimal to redistribution of circulating trophic cells from spontaneous leukemogenesis in the BM, and to reparation of the inducible sublethal injuries in normal tissues [154] [155]. Thus, the proposed explanation does not compromise the top priority/pre-eminence of the NLT model [147] [154] [155] and shows haw tissues injures mimic the stimulation of the anti-tumor, immune defense.

The proposed destructive and distractive mechanisms explaining the successful clinical use of low dose TBI and HBI [115] [117] [124] [136] [135] [157] [158] [159] were applicable to systemic treatments with any cytotoxic agents, without the need for any "stimulation" of immunity [160]. For instance, fractional longitudinal irradiation of the lower part of the body (HBI) in patients with relapsed ovarian epithelial cancer (four courses $0.1 \mathrm{~Gy} \times 10$ daily; cumulative dose $4 \mathrm{~Gy}$ ) contributed to longevity more (average life span of patients 42.6 months), or at least not less, than did conventional chemotherapy with carboplatinum and docetaxel (average life span 29.3 months) [115]. Both schemes could not be able to destroy tumor tissue directly. Actually, biologically effective dose of HBI in this study was approximately $1 \mathrm{~Gy}$, taking account of changes in dose-per-fraction and overall time of tissues reparation/regeneration [161]. Therefore, HBI was not be enough for indirect destructive control of tumor growth like chemotherapy did, and should be classified, as "distracting" compared to chemotherapy.

\section{Conclusions}

Widely used conventional doses of anticancer drugs as well as TBI/HBI for systemic therapy are too low to control tumor growth directly. The application of the trophic/morphogenesis function of HSC and their trophic lymphoid descendants to the main sites of a distant cancer show that temporary benefit arises indirectly, due to either destruction or to competitive distraction of circulating trophic cells from proliferating quasi-embryonic malignant targets, to reparate/regenerate a multitude of sublethally injured normal cells. Because chemotherapy and radiation both induce similar types of DNA damage for cell cycle arrest throughout of the body, there is no strong argument for overestimation of the therapeutic efficiency of systemic chemotherapy or for the underestimation 
of TBI/HBI therapeutic approaches. A temporary benefit from all systemic/indirect treatments, as well as the subsequent irreversible resistance to them, first develops because of temporary and moderate restriction of trophic cell reproduction in lymphopoiesis and, second, results from its steady exhaustion as the most amortizable system in the host organism. A lowered resource of generation of trophic lymphoid stem cells is in agreement with a lowered incidence/mortality/prevalence of cancer during the last decades of life. The trophic influence of lymphopoiesis on cancer development eliminates conflict with the LNT theory that involves the importance of anti-tumor immunity, when the phenomenon of radiation hormesis is explained. The trophic function of circulating cells of BM origin is also compatible with such syndromes as preeclampsia, MODS, frailty at senility, and other infirmities of trophic origin.

Long-standing controversy surrounding the cancer immunosurveillance hypothesis of Thomas (1959) and Burnet (1970), as well as the concept of Dunn and colleagues (2004) that a malignant cell has capacity to evade the suppressor functions of the immune system by "immunoediting" do not take into account a trophic property of circulating mononuclear cells. This review opens first principally new potential for reconsidering of long-lived fundamental doctrine of anticancer immunity on the base of natural function of circulating cells of bone marrow-origin to support a growth and regeneration of own body regardless of their malignant or non-malignant nature. The overview, despite its fragmentary nature, discusses the fundamental and practical applicability of alternative trophic mechanisms in a wide range of pathologies. Further comprehensive research is needed at the level of vital physiological systems, which will facilitate the discovery of more hidden curative opportunities associated with circulating stem cells and immature lymphocytes.

\section{Acknowledgements}

None of contributed substantially apart the author.

\section{Conflicts of Interest}

No. Regular financial support of the Ministry of Health in accordance with the open scientific plan of the laboratory without any reservations regarding the open publication of the expected results.

\section{References}

[1] Bruno, A., Pagani, A., Pulze, L., et al. (2014) Orchestration of Angiogenesis by Immune Cells. Frontiers in Oncology, 4, 131. https://doi.org/10.3389/fonc.2014.00131

[2] Shutko, A.N., Shatinina, N.N., Lubotskaia, L.S. and Ekimova, L.P. (1981) Lymphocyte Trophic Function as a Potential Reserve in Improving Results of Tumor Radiotherapy. Meditsinskaia Radiologiia, 26, 39-44.

https://www.ncbi.nlm.nih.gov/pubmed/6894957 https://elbrary.ru/contents.asp?titleid=7883

[3] Yu, P. and Fu, Y.X. (2006) Tumor-Infiltrating T Lymphocytes: Friends or Foes? 
Laboratory Investigation, 86, 231-245. https://doi.org/10.1038/labinvest.3700389

[4] Ruffell, B., De Nardo, D.G., Affara, N.I. and Coussens, L.M. (2010) Lymphocytes in Cancer Development: Polarization towards Pro-Tumor Immunity. Cytokine \& Growth Factor Reviews, 21, 3-10. https://doi.org/10.1016/j.cytogfr.2009.11.002

[5] Drapeau, C. (2010) Cracking the Stem Cell Code: Demystifying the Most Dramatic Scientific Breakthrough of Our Times. Sutton Hart Press, Hillsboro.

[6] Maltby, S., Freeman, S., Gold, M.J., et al. (2011) Opposing Roles for CD34 in B16 Melanoma Tumor Growth Alter Early Stage Vasculature and Late Stage Immune Cell Infiltration. PLoS ONE, 6, e18160. https://doi.org/10.1371/journal.pone.0018160

[7] Rennert, R.C., Sorkin, M., Gargand, R.K. and Gurtner, G.C. (2012) Stem Cell Recruitment after Injury: Lessons for Regenerative Medicine. Regenerative Medicine, 7, 833-850. https://doi.org/10.2217/rme.12.82

[8] Zidlik, V., Brychtova, S., Uvirova, M., Ziak, D. and Dvorackova, J. (2015) The Changes of Angiogenesis and Immune Cell Infiltration in the Intra- and Peri-Tumoral Melanoma Microenvironment. International Journal of Molecular Sciences, 16, 7876-7889. https://doi.org/10.3390/ijms16047876

[9] Finkin, S., Yuan, D., Stein, I., et al. (2015) Ectopic Lymphoid Structures Function as Microniches for Tumor Progenitor Cells in Hepatocellular Carcinoma. Nature Immunology, 16, 1235-1244. https://doi.org/10.1038/ni.3290

[10] Patman, G. (2015) Hepatocellular Carcinoma: Ectopic Lymphoid Structures Promote Carcinogenesis in the Liver. Nature Reviews Gastroenterology \& Hepatology, 12, 671. https://doi.org/10.1038/nrgastro.2015.192

[11] Ashman, L.K. and Aylett, G.W. (1991) Expression of CD31 Epitopes on Human Lymphocytes: CD31 Monoclonal Antibodies Differentiate between Naive (CD45RA+) and Memory (CD45RA-) CD4-Positive T Cells. Tissue Antigens, 38, 208-212. https://doi.org/10.1111/j.1399-0039.1991.tb01899.x

[12] Hur, J., Yang, H.M., Yoon, C.H., et al. (2007) Identification of a Novel Role of T Cells in Postnatal Vasculogenesis. Characterization of Endothelial Progenitor Cell Colonies. Circulation, 116, 1671-1682. https://doi.org/10.1161/CIRCULATIONAHA.107.694778

[13] Domea, B., Timar, J., Ladanyi, A., et al. (2008) Circulating Endothelial Cells, Bone Marrow-Derived Endothelial Progenitor Cells and Proangiogenic Hematopoietic Cells in Cancer: From Biology to Therapy. Critical Reviews in Oncology/Hematology, 69, 108-124. https://doi.org/10.1016/j.critrevonc.2008.06.009

[14] Yu, H.-K., Lee, H.-J., Choi, H.-N., et al. (2013) Characterization of CD45-/CD31+/CD105+ Circulating Cells in the Peripheral Blood of Patients with Gynecologic Malignancies. Clinical Cancer Research, 19, 5340-5350. https://doi.org/10.1158/1078-0432.CCR-12-3685

[15] Kucia, M., Ratajczak, J. and Ratajczak, M.Z. (2005) Bone Marrow as a Source of Circulating CXCR4+ Tissue-Committed Stem Cells. Biology of the Cell, 97, 133-146. https://doi.org/10.1042/BC20040069

[16] Shoutko, A.N., Gerasimova, O.A., Ekimova, L.P., et al. (2016) Long-Term Activation of Circulating Liver-Committed Mononuclear Cells after OLT. Journal of Regenerative Medicine, 1, 011.

https://jacobspublishers.com/long-term-activation-of-circulating-liver-committed$\underline{\text { mon... }}$

[17] Xiong, Y., Russell, D.L., McDonald, L.T., Cowart, L.A. and La Rue, A.C. (2017) Hematopoietic Stem Cell-Derived Adipocytes Promote Tumor Growth and Cancer 
Cell Migration. International Journal of Cancer Research and Molecular Mechanisms, 3.

[18] Templeton, A.J., McNamara, M.G., Šeruga, B., et al. (2014) Prognostic Role of Neutrophil-to-Lymphocyte Ratio in Solid Tumors: A Systematic Review and Meta-Analysis. Journal of the National Cancer Institute, 106, dju124. https://doi.org/10.1093/jnci/dju124

[19] Cho, U., Park, H.S., Im, S.Y., et al. (2018) Prognostic Value of Systemic Inflammatory Markers and Development of a Nomogram in Breast Cancer. PLoS ONE, 13, e0200936. https://doi.org/10.1371/journal.pone.0200936

[20] da Costa, J.P., Vitorino, R., Silva, G.M., et al. (2016) A Synopsis on Aging-Theories, Mechanisms and Future Prospects. Ageing Research Reviews, 29, 90-112. https://doi.org/10.1016/j.arr.2016.06.005

[21] Clegg, A., Young, J., Iliffe, S., Rikkert, M.O. and Rockwood, K. (2013) Frailty in Older People. The Lancet, 381, 752-762.

https://doi.org/10.1016/S0140-6736(12)62167-9

[22] Drew, W., Wilson, D. and Sapey, E. (2017) Frailty and the Immune System. Journal of Ageing Research and Health Care, 2, 1-14.

https://doi.org/10.14302/issn.2474-7785.jarh-17-1578

[23] Bengtson, V.L., Gans, D., Putney, N.M. and Silverstein, M. (2009) Theories about Age and Aging. In: Bengtson, V.L., Silverstein, M., Putney, N.M. and Gans, D., Eds., Handbook of Theories of Aging, Gans Springer Publishing Company, New York, 3-24.

http://lghttp.48653.nexcesscdn.net/80223CF/springer-static/media/samplechapters/ 9780826129420/9780826129420_chapter.pdf

[24] Sun, L., Brown, R., Chen, S., Zhuge, Q. and Su, D.M. (2012) Aging Induced Decline in T-Lymphopoiesis Is Primarily Dependent on Status of Progenitor Niches in the Bone Marrow and Thymus. Aging, 4, 606-619. https://doi.org/10.18632/aging.100487

[25] Małkiewicz, A. and Dziedzic, M. (2012) Aging Bone Marrow Reconversion-Imaging of Physiological Changes in Bone Marrow. Polish Journal of Radiology, 77, 45-50. https://doi.org/10.12659/PJR.883628

[26] Moresi, R., Tesei, S., Costarelli, L., et al. (2005) Age- and Gender-Related Alterations of the Number and Clonogenic Capacity of Circulating CD34+ Progenitor Cells. Biogerontology, 6, 185-192. https://doi.org/10.1007/s10522-005-7954-5

[27] Al Mheid, I., Hayek, S.S., Ko, Y.A., et al. (2016) Age and Human Regenerative Capacity Impact of Cardiovascular Risk Factors. Circulation Research, 119, 801-809. https://doi.org/10.1161/CIRCRESAHA.116.308461

[28] Chen, X., Mao, G. and Leng, S.X. (2014) Frailty Syndrome: An Overview. Clinical Interventions in Aging, 9, 433-441.

[29] Gajraa, A., Klepinb, H.D., Fengc, T., et al. (2015) Predictors of Chemotherapy Dose Reduction at First Cycle in Patients Age 65 Years and Older with Solid Tumors. Journal of Geriatric Oncology, 6, 133-140.

[30] Li, J., Chen, Q., Luo, X., Hong, J., et al. (2015) Neutrophil-to-Lymphocyte Ratio Positively Correlates to Age in Healthy Population. Journal of Clinical Laboratory Analysis, 29, 437-443. https://doi.org/10.1002/jcla.21791

[31] Mizock, B.A. (2009) The Multiple Organ Dysfunction Syndrome. Disease-A-Month, 55, 476-526. https://doi.org/10.1016/j.disamonth.2009.04.002

[32] Nickson, C. (2016) Multi-Organ Dysfunction Syndrome (MODS). Life in the Fas- 
tlane. https://lifeinthefastlane.com/ccc/multi-organ-dysfunction-syndrome-mods/

[33] Manson, J., Cole, M.E., De'Ath, H.D., et al. (2016) Early Changes within the Lymphocyte Population Are Associated with the Development of Multiple Organ Dysfunction Syndrome in Trauma Patients. Critical Care, 20, 176.

https://doi.org/10.1186/s13054-016-1341-2

[34] Arias, E., Rostron, B.L. and Tejada-Vera, B. (2010) United States Life Tables, 2006. National Vital Statistics Reports, 58, 1-40. https://www.cdc.gov/nchs/data/nvsr/nvsr58/nvsr58_10.pdf

[35] Weon, B.M. and Je, J.H. (2012) Trends in Scale and Shape of Survival Curves. Scientific Reports, 2, 504. https://doi.org/10.1038/srep00504

[36] Williams, D.E. (2014) National Population Projections: 2012-Based Reference Volume Series PP2. Chapter 5: Mortality, 2012-Based NPP Reference Volume. https://www.ons.gov.uk/peoplepopulationandcommunity/populationandmigration/ pop...

[37] Veerbeek, J.H.W., Nikkels, P.G.J., Torrance, H.L., et al. (2014) Placental Pathology in Early Intrauterine Growth Restriction Associated with Maternal Hypertension. Placenta, 35, 696-701. https://doi.org/10.1016/j.placenta.2014.06.375

[38] Harmon, A.C., Cornelius, D.C., Amaral, L.M., et al. (2016) The Role of Inflammation in the Pathology of Preeclampsia. Clinical Science, 130, 409-419. https://doi.org/10.1042/CS20150702

[39] Luppi, P., Powers, R.W., Verma, V., et al. (2010) Maternal Circulating CD34+ VEGFR-2+ and CD133+ VEGFR-2+ Progenitor Cells Increase during Normal Pregnancy But Are Reduced in Women with Preeclampsia. Reproductive Sciences, 17, 643-652. https://doi.org/10.1177/1933719110366164

[40] Cornelius, D.C. (2018) Preeclampsia: From Inflammation to Immunoregulation. Clinical Medicine Insights: Blood Disorders, 11, 1179545X17752325.

[41] Uzan, J., Carbonnel, M., Piconne, O., Asmar, R. and Ayoubi, J.-M. (2011) Pre-Eclampsia: Pathophysiology, Diagnosis, and Management. Vascular Health and Risk Management, 7, 467-474.

[42] Skjaerven, R., Wilcox, A.J., Klungsøyr, K., et al. (2012) Cardiovascular Mortality after Pre-Eclampsia in One Child Mothers: Prospective, Population Based Cohort Study. BMJ, 345, e7677. https://doi.org/10.1136/bmj.e7677

[43] CDC (Centers for Disease Control), All Females by Age Group (2015) 2015 Women's Health CDC. Leading Causes of Death (LCOD) by Age Group, All Females-United States, (Current Listing). https://www.cdc.gov/women/lcod/2015/all-females/index.htm

[44] Muzzio, D.O., Ziegler, K.B., Ehrhardt, J., Zygmunt, M. and Jensen, F. (2016) Marginal Zone B Cells Emerge as a Critical Component of Pregnancy Well-Being. Reproduction, 151, 29-37. https://doi.org/10.1530/REP-15-0274

[45] Cofre, J. and Abdelhay, E. (2017) Cancer Is to Embryology as Mutation Is to Genetics: Hypothesis of the Cancer as Embryological Phenomenon. Scientific World Journal (Hindawi), 2017, Article ID: 3578090. https://doi.org/10.1155/2017/3578090

[46] de Lima, T.M., Lima, M.M., Almeida, D.C., Mendonça, J.R. and Curi, R. (2005) Cachexia Induced by Walker 256 Tumor Growth Causes Rat Lymphocyte Death. Cancer Immunology, Immunotherapy, 54, 179-186. https://doi.org/10.1007/s00262-004-0570-4

[47] de Lima, C., Alves, L.E., Iagher, F., et al. (2008) Anaerobic Exercise Reduces Tumor 
Growth, Cancer Cachexia and Increases Macrophage and Lymphocyte Response in Walker 256 Tumor-Bearing. European Journal of Applied Physiology, 104, 957-964. https://doi.org/10.1007/s00421-008-0849-9

[48] Vanhoutte, G., van de Wiel, M., Wouters, K., et al. (2016) Cachexia in Cancer: What Is in the Definition? BMJ Open Gastroenterology, 3, e000097. https://doi.org/10.1136/bmjgast-2016-000097

[49] Sepesi, B., Cuentes, E.P., Canales, J.R., et al. (2017) Tumor-Infiltrating Lymphocytes and Overall Survival in surgically Resected Stage II and III Nonesmall Cell Lung Cancer. International Journal of Radiation Oncology, Biology, Physics (IJROBP), 98, 223. https://doi.org/10.1016/j.ijrobp.2017.01.060

[50] Eerola, A.-K., Soini, Y. and Paakko, P.A. (2000) High Number of Tumor-Infiltrating Lymphocytes Are Associated with a Small Tumor Size, Low Tumor Stage, and a Favorable Prognosis in Operated Small Cell Lung Carcinoma. Clinical Cancer Research, 6, 1875-1881.

[51] Rathore, A.S., Goel, M.M., Makker, A., Kumar, S. and Srivastava, A.N. (2013) Prognostic Impact of CD3 Tumor Infiltrating Lymphocytes in Triple-Negative Breast Cancer. Indian Journal of Clinical Practice, 24, 376-389. http://medind.nic.in/iaa/t13/i9/iaat13i9p376.pdf

[52] Bromwich, E.J., Mc Ardle, P.A., Canna, K., et al. (2003) The Relationship between T-Lymphocyte Infiltration, Stage, Tumour Grade and Survival in Patients Undergoing Curative Surgery for Renal Cell Cancer. British Journal of Cancer, 89, 1906-1908.

[53] Carvalho, M.I., Pires, I., Dias, M., et al. (2015) Intratumoral CD3+ T-lymphocytes Immunoexpression and Its Association With c-kit, Angiogenesis, and Overall Survival in Malignant Canine Mammary Tumor. Analytical Cellular Pathology, 6, Article ID: 920409.

[54] Mao, Y., Qu, Q., Chen, X., et al. (2016) The Prognostic Value of Tumor-Infiltrating Lymphocytes in Breast Cancer: A Systematic Review and Meta-Analysis. PLoS ONE, 11, e0152500. https://doi.org/10.1371/journal.pone.0152500

[55] Patman, G. (2015) Ectopic Lymphoid Structures Promote Carcinogenesis in the Liver Nature Reviews. Gastroenterology \& Hepatology, 12, 671. https://doi.org/10.1038/nrgastro.2015.192

[56] Sautès-Fridman, C. and Fridman, W.H. (2016) TLS in Tumors: What Lies Within. Trends in Immunology, 37, 1-2. https://doi.org/10.1016/j.it.2015.12.001

[57] Colbeck, E.J., Ager, A., Gallimore, A. and Jones, G.W. (2017) Tertiary Lymphoid Structures in Cancer: Drivers of Antitumor Immunity, Immunosuppression, or Bystander Sentinels in Disease? Frontiers in Immunology, 8, 1830. https://doi.org/10.3389/fimmu.2017.01830

[58] Calderaro, J., Petitprez, F., Becht, E., et al. (2018) Intra-Tumoral Tertiary Lymphoid Structures Area Associated with a Low Risk of Early Recurrence of Hepatocellular Carcinoma. Journal of Hepatology, 70, 58-65.

https://doi.org/10.1016/j.jhep.2018.09.003

[59] Habner, B.A. (2011) General Principles of Cancer Chemotherapy. In: Brunton, L.L., Ed., Goodman and Gilman's the Pharmacological Basis of Therapeutics, 12 Edition, McGraw Medical, New York, 1667-1670.

[60] Berreta, G. (1983) Cancer Chemotherapy Regimens. Farmitalia Carlo Erba, Milano.

[61] Liesveld, J.L., Rubin, Ph. and Constine, L.S. (2014) Hematopoietic System. In: Rubin, Ph., Constine, L.S. and Marks, L.B., Eds., Adverse Late Effects of Cancer 
Treatment, Vol. 2: Normal Tissue Specific Sites and Systems, Springer Verlag, Heidelberg, 623-656. https://doi.org/10.1007/978-3-540-75863-1_24

[62] Kopjar, N., Kasuba, V., Rozgaj, R., et al. (2009) The Genotoxic Risk in Health Care Workers Occupationally Exposed to Cytotoxic Drugs-A Comprehensive Evaluation by the SCE Assay. Journal of Environmental Science and Health, Part A, 44, 462-79. https://doi.org/10.1080/10934520902719845

[63] Greaves, P. (2012) Small Intestine. In: Greaves, P., Ed., Histopathology of Preclinical Toxicity Studies, Interpretation and Relevance in Drug Safety Studies, Elsevier AP, Amsterdam/Boston/Heidelberg, London, 372-391.

[64] Swift, L.H. and Golsteyn, R.M. (2014) Genotoxicanti-Cancer Agents and Their Relationship to DNA Damage, Mitosis, and Checkpoint Adaptation in Proliferating Cancer Cells. International Journal of Molecular Sciences, 15, 3403-3431. https://doi.org/10.3390/ijms15033403

[65] Arnon, J., Meirow, D., Lewis-Roness, H. and Ornoy, A. (2001) Genetic and Teratogenic Effects of Cancer Treatments on Gametes and Embryos. Human Reproduction Update, 7, 394-403. https://doi.org/10.1093/humupd/7.4.394

[66] Vyas, D., Laput, G. and Vyas, A.K. (2014) Chemotherapy-Enhanced Inflammation May Lead to the Failure of Therapy and Metastasis. OncoTargets and Therapy, 7, 1015-1023. https://doi.org/10.2147/OTT.S60114

[67] American Cancer Society (2016) Cancer Treatment \& Survivorship Facts \& Figures 2016-2017. Estimated Numbers of Cancer Survivors by State as of January 1, Atlanta. https://www.cancer.org/.../cancer-org/.../cancer-facts-and.../c

[68] Guillerman, R.P. (2013) Marrow: Red, Yellow and Bad. Pediatric Radiology, 43, 181-192. https://doi.org/10.1007/s00247-012-2582-0

[69] Liu, L.-T., Chen, Q.-Y., Tang, L.-Q., et al. (2018) The Prognostic Value of Treatment-Related Lymphopenia in Nasopharyngeal Carcinoma Patients. Cancer Research and Treatment, 50, 19-29.

[70] Brower, V. (2013) Tracking Chemotherapy's Effects on Secondary Cancers. JNCI, 105, 1421-1422. https://doi.org/10.1093/jnci/djt273

[71] Marsh, J.C. (1979) Comparison of the Sensitivities of Human, Canine, and Murine Hematopoietic Precursor Cells to Adriamycin and n-Trifluoroacetyladriamycin-14 valerate 1. Cancer Research, 39, 360-364.

http://cancerres.aacrjournals.org/content/canres/39/2_Part_1/360.full.pdf

[72] Hurria, A. and Lichtman, S.M. (2008) Clinical Pharmacology of Cancer Therapies in Older Adults. British Journal of Cancer, 98, 517-522. https://doi.org/10.1038/sj.bjc.6604201

[73] Siegel, M.J. (2011) MRI of Bone Marrow. 169-179. https://pdfs.semanticscholar.org/69ec/de155073c21602f1ac1c76a18bcf144ba924.pdf

[74] Richardson, R.B. (2009) Ionizing Radiation and Aging: Rejuvenating an Old Idea. Aging (Albany NY), 1, 887-902. https://doi.org/10.18632/aging.100081

[75] Richardson, R.B., Allan, D.S. and Le, Y. (2014) Greater Organ Involution in Highly Proliferative Tissues Associated with the Early Onset and Acceleration of Ageing in Humans. Experimental Gerontology, 55, 80-91. https://doi.org/10.1016/j.exger.2014.03.015

[76] Braga, S. (2011) Why Do Our Patients Get Chemotherapy until the End of Life? Annals of Oncology, 22-23, 45-48. https://doi.org/10.1093/annonc/mdr416

[77] Karim, S.M., Zekri, J., Abdelghany, E., et al. (2015) Time from Last Chemotherapy to Death and Its Correlation with the End of Life Care in a Referral Hospital. Indian 
Journal of Medical and Paediatric Oncology, 36, 55-59. https://doi.org/10.4103/0971-5851.151792

[78] Bailey, C.H., Jameson, G., Sima, C.E., et al. (2012) Progression-Free Survival Decreases with Each Subsequent Therapy in Patients Presenting for Phase I Clinical Trials. Journal of Cancer, 3, 7-13. https://doi.org/10.7150/jca.3.7

[79] (2018) Common Terminology Criteria for Adverse Events (CTCAE). Protocol Development, National Cancer Institute, Division of Cancer Treatment and Diagnosis (DCTD). CTCAE v5.0 Clean, Tracked, and Mapping Document (Excel) (November 27, 2017).

https://ctep.cancer.gov/protocoldevelopment/electronic_applications/ctc.htm\#ctc_5 $\underline{0}$

[80] Shoutko, A.N. and Mus, V.F. (2018) Potential of Hematopoietic Stem Cells and Mitotic Activity in Peripheral Lymphocytes to Predict Life Expectancy of Patients with Metastatic Non-Small Cell Lung Cancer after Conventional Therapy. Advances in Molecular Imaging ( $A M I)$, 8, 25-37.

[81] Shoutko, A.N. and Ekimova, L.P. (2014) Lymphocytopenia Can Contribute in Common Benefit of Cytotoxic Therapy of Cancer. Inter-Medical, 3, 5-13.

http://www.inter-medical.ru/files/Archiv/26-27

[82] Shoutko, A.N., Gerasimova, O.A., Ekimova, L.P., et al. (2017) Lymphocyte Reproductive Activity Normalized to Numbers of Hematopoietic Stem Cells in Blood and Rate of Death in Fatal Diseases. International Journal of Genetics and Genomics, 5 , 54-62. https://doi.org/10.11648/j.ijgg.20170505.12

[83] Shoutko, A., Ekimova, L., Mus, V. and Sokurenko, V. (2012) Fluctuations of CD34+ Cells Number in Blood of Cancer Patients during Final Year of Life. Medical and Health Science Journal, 13, 7-13.

[84] Wao, H., Mhaskar, R., Kumar, A., Miladinovic, B. and Djulbegovic, B. (2013) Survival of Patients with Non-Small Cell Lung Cancer without Treatment: A Systematic Review and Meta-Analysis. Systematic Reviews, 2, 10.

https://doi.org/10.1186/2046-4053-2-10 http://www.systematicreviewsjournal.com/content/2/1/10

[85] Pallis, A.G., Gridelli, C., Wedding, U., Faivre-Finn, C., Veronesi, G., Jaklitsch, M., Luciani, A. and O’Brien, M. (2014) Management of Elderly Patients with NSCLC; Updated Expert's Opinion Paper: EORTC Elderly Task Force, Lung Cancer Group and International Society for Geriatric Oncology. Annals of Oncology, 25, 1270-1283. https://doi.org/10.1093/annonc/mdu022

[86] Baker, H. (2015) Overtreatment in Stage IV Lung Cancer in the USA. The Lancet Oncology, 16, e532. https://doi.org/10.1016/S1470-2045(15)00383-6

[87] Koshy, M., Malik, R., Mahmood, U., Husain, Z., Weichselbaum, R.R. and Sher, D.J. (2015) Prevalence and Predictors of Inappropriate Delivery of Palliative Thoracic Radiotherapy for Metastatic Lung Cancer. JNCI: Journal of the National Cancer Institute, 107, djv278. https://doi.org/10.1093/jnci/djv278

[88] Light, D. and Lexchin, J. (2015) Why Do Cancer Drugs Get Such an Easy Ride? BMJ, 350, h2068. https://doi.org/10.1136/bmj.h2068

[89] John, S. and Broggio, J. (2019) National Statistic. Dataset: Cancer Survival in England. Adults Diagnosed.

https://www.ons.gov.uk/peoplepopulationandcommunity/healthandsocialcare/cond itionsanddiseas-

$\underline{\text { es/datasets/cancersurvivalratescancersurvivalinenglandadultsdiagnosed }}$ 
[90] SEER Cancer Statistics Review (CSR) 1975-2015. https://seer.cancer.gov/csr/1975_2015/revisions.html

[91] Sacdalan, D.B., Lucero, J.A. and Sacdalan, D.L. (2018) Prognostic Utility of Baseline Neutrophil-to-Lymphocyte Ratio in Patients Receiving Immune Checkpoint Inhibitors: A Review and Meta-Analysis. OncoTargets and Therapy, 11, 955-965. https://doi.org/10.2147/OTT.S153290

[92] Shibutani, M., Maeda, K., Nagahara, H., et al. (2017) Prognostic Significance of the Preoperative Lymphocyte-to-Monocyte Ratio in Patients with Colorectal Cancer. Oncology Letters, 13, 1000-1006. https://doi.org/10.3892/ol.2016.5487

[93] Moschetta, M., Uccello, M., Kasenda, B., et al. (2017) Dynamics of Neutrophils-to-Lymphocyte Ratio Predict Outcomes of PD-1/PD-L1 Blockade. BioMed Research International, 2017, Article ID: 1506824.

https://doi.org/10.1155/2017/1506824

[94] Abdellatif, H. and Shiha, G. (2018) PD-L1 Expression on Circulating CD34+ Hematopoietic Stem Cells Closely Correlated with t-Cell Apoptosis in Chronic Hepatitis C Infected Patients. International Journal of Stem Cells, 11, 78-86. https://doi.org/10.15283/ijsc17047

[95] Lissoni, P., Brivio, F., Fumagalli, L., et al. (2009) Effects of the Conventional Antitumor Therapies Surgery, Chemotherapy, Radiotherapy and Immunotherapy on Regulatory T Lymphocytes in Cancer Patients. Anticancer Research, 29, 1847-1852.

[96] Chaudhary, B. and Elkord, E. (2016) Regulatory T Cells in the Tumor Microenvironment and Cancer Progression: Role and Therapeutic Targeting. Vaccines (Basel), 4, 28. https://doi.org/10.3390/vaccines 4030028

[97] Xu, C., Yang, S.P., Zhang, Y., et al. (2018) Neutropenia During the First Cycle of Induction Chemotherapy Is Prognostic for Poor Survival in Locoregionally Advanced Nasopharyngeal Carcinoma: A Real-World Study in an Endemic Area. Cancer Research and Treatment, 50, 777-790. https://doi.org/10.4143/crt.2017.255

[98] Du, X., Tang, F., Liu, M., et al. (2018) A Reappraisal of CTLA-4 Checkpoint Blockade in Cancer Immunotherapy. Cell Research, 28, 416-432.

[99] Hryniewicki, A.T., Wang, C., Shatsky, R.A. and Coyne, C.J. (2018) Management of Immune Checkpoint Inhibitor Toxicities: A Review and Clinical Guideline for Emergency Physicians. Journal of Emergency Medicine, 55, 489-502. https://doi.org/10.1016/j.jemermed.2018.07.005

[100] Harding, C., Pompei, F. and Wilson, R. (2012) Peak and Decline in Cancer at Old Ages. Cancer, 118, 1371-1386. https://doi.org/10.1002/cncr.26376

[101] National Center for Health Statistics (2016) LCWK1 Deaths, Percent of Total Deaths, and Death Rates for the 15 Leading Causes of Death in 5-Year Age Groups, by Race and Hispanic Origin, and Sex: United States. https://www.cdc.gov/nchs/data/dvs/lcwk/lcwk1_hr_2016.pdf

[102] Rivard, A., Fabre, J.-E., Silver, M., et al. (1999) Age-Dependent Impairment of Angiogenesis. Circulation, 99, 111-120. https://doi.org/10.1161/01.CIR.99.1.111

[103] Weedon-Fekjær, H., Lindqvist, B.H., Vatten, L.J., Aalen, O.O. and Tretli, S. (2008) Breast Cancer Tumor Growth Estimated through Mammography Screening Data. Breast Cancer Research, 10, R41. https://doi.org/10.1186/bcr2092

[104] Natale, G. and Bocci, G. (2017) Tumor Dormancy, Angiogenesis and Metronomic Chemotherapy. In: Wang, Y. and Crea, F., Eds., Tumor Dormancy and Recurrence, Humana Press, Springer Int. Publ., Cham, 31-50.

https://doi.org/10.1007/978-3-319-59242-8_3 
[105] Dorshkind, K., Montecino-Rodriguez, E. and Signer, R.A. (2009) The Ageing Immune System: Is It Ever Too Old to Become Young Again? Nature Reviews Immunology, 9, 57-62. https://doi.org/10.1038/nri2471

[106] Franceschi, C., Capri, M., Monti, D., et al. (2007) Inflammaging and Anti-Inflammaging: A Systemic Perspective on Aging and Longevity Emerged from Studies in Humans. Mechanisms of Ageing and Development, 128, 92-105. https://doi.org/10.1016/j.mad.2006.11.016

[107] Shoutko, A.N. and Ekimova, L.P. (2014) The Impact of Middle Age on the Viability of Patients with Nonmalignant and Malignant Diseases. Cancer Research Journal, 2, 114-120. https://doi.org/10.11648/j.crj.20140206.14

[108] Propert, K.J. and Anderson, J.R. (1988) Assessing the Effect of Toxicity on Prognosis: Methods of Analysis and Interpretation. JCO, 6, 868-870.

https://doi.org/10.1200/JCO.1988.6.5.868

[109] Tewari, K.S., Java, J.J., Gatcliffe, T.A., Bookman, M.A. and Monk, B.J. (2014) Chemotherapy-Induced Neutropenia as a Biomarker of Survival in Advanced Ovarian Carcinoma: An Exploratory Study of the Gynecologic Oncology Group. Gynecologic Oncology, 133, 439-445. https://doi.org/10.1016/j.ygyno.2014.03.013

[110] Su, Z., Mao, Y.-P., OuYang, P.-Y., et al. (2015) Leucopenia and Treatment Efficacy in Advanced Nasopharyngeal. BMC Cancer, 15, 429.

[111] van Zant, G. and Liang, Y. (2012) Concise Review: Hematopoietic Stem Cell Aging, Life Span, and Transplantation. Stem Cells Translational Medicine, 1, 651-657. https://doi.org/10.5966/sctm.2012-0033

[112] Zhu, L., Zhou, L.K., Xue, M., et al. (2009) Factors Impacting Yield of CD34(+) Cells from Healthy Donors Mobilized with rhG-CSF. Journal of Experimental Hematology, 17, 1541-45.

[113] Colmegna, I., Diaz-Borjon, A., Fujii, H., et al. (2008) Defective Proliferative Capacity and Accelerated Telomeric Loss of Hematopoietic Progenitor Cells in Rheumatoid Arthritis. Arthritis \& Rheumatology, 58, 990. https://doi.org/10.1002/art.23287

[114] Pang, W.W., Price, E.A., Sahoo, D., et al. (2011) Human Bone Marrow Hematopoietic Stem Cells Are Increased in Frequency and Myeloid-Biased with Age. Proceedings of the National Academy of Sciences, 108, 20012-20017. https://doi.org/10.1073/pnas.1116110108

[115] Shoutko, A.N., Yurkova, L.E., Borodulya, K.S. and Ekimova, L.P. (2016) Protracted Half-Body Irradiation Instead of Chemotherapy: Life Span and Lymphocytopenia in Relapsed Ovarian Cancer. International Journal of Tumor Therapy, 5, 1-7.

[116] Yoon, J.-H., Kim, H.-J. and Min, W.-S. (2017) Comparison of the Effects of Early Intensified Induction Chemotherapy and Standard 3+7 Chemotherapy in Adult Patients with Acute Myeloid Leukemia. Blood Research, 52, 174-183. https://doi.org/10.5045/br.2017.52.3.17

[117] Shoutko, A.N., Yurkova, L.E., Borodulya, K.S., Ekimova, L.P. and Matyurin K.S. (2017) Competitive Principal of Tumor Control in Radiological Clinic. Radiology and Diagnostic Imaging, 1, 1-2.

[118] Barnett, G.C., West, C.M., Dunning, A.M., et al. (2009) Normal Tissue Reactions to Radiotherapy: Towards Tailoring Treatment Dose by Genotype. Nature Reviews Cancer, 9, 134-142. https://doi.org/10.1038/nrc2587

[119] Bracci, L., Schiavoni, G., Sistigu, A. and Belardelli, F. (2014) Chemotherapeutic Agents Stimulate Both the Innate and Adaptive Arms of the Immune System. Cell Death and Differentiation, 21, 15-25. 
[120] ElKaffas, A., Giles, A. and Czarnota, G.J. (2013) Dose-Dependent Response of Tumor Vasculature to Radiation Therapy in Combination with Sunitinib Depicted by Threedimensional High-Frequency Power Doppler Ultrasound. Angiogenesis, 16, 443-454.

[121] El Kaffas, A., Gangeh, M.J., Farhat, G., et al. (2018) Tumour Vascular Shutdown and Cell Death Following Ultrasound-Microbubble Enhanced Radiation Therapy. Theranostics, 8, 314-327. https://doi.org/10.7150/thno.19010

[122] Jayson, G.C., Hicklin, D.J. and Ellis, L.M. (2012) Antiangiogenic Therapy-Evolving View Based on Clinical Trial Results. Nature Reviews Clinical Oncology, 9, 297-303. https://doi.org/10.1038/nrclinonc.2012.8

[123] Guo, S. and Deng, C.X. (2018) Effect of Stromal Cells in Tumor Microenvironment on Metastasis Initiation. International Journal of Biological Sciences, 14, 2083-2093. http://www.ijbs.com/v14p2083.htm https://doi.org/10.7150/ijbs.25720

[124] Kojima, S., Tsukimoto, M., Shimura, N., et al. (2017) Treatment of Cancer and Inflammation with Low-Dose Ionizing Radiation: Three Case Reports. Dose Response, 15, 1559325817697531. https://doi.org/10.1177/1559325817697531

[125] Shoutko, A.N., Yurkova, L.E., Borodulya, K.S. and Ekimova, L.P. (2015) Lymphocytopenia and Cytotoxic Therapy in Patients with Advanced Ovarian Cancer. Cancer Research Journal, 3, 47-51. https://doi.org/10.11648/j.crj.20150303.11

[126] Hayman, J.A., Callahan, J.W., Herschtal, A., et al. (2011) Distribution of Proliferating Bone Marrow in Adult Cancer Patients Determined Using Flt-Pet Imaging. International Journal of Radiation Oncology, Biology, Physics, 79, 847-852. https://doi.org/10.1016/j.ijrobp.2009.11.040

[127] Garau, M.M., Calduch, A.L. and López, E.C. (2011) Radiobiology of the Acute Radiation Syndrome. Reports of Practical Oncology and Radiotherapy, 16, 123-130. https://doi.org/10.1016/j.rpor.2011.06.001

[128] Di Carlo, A.L., Maher, C., Hick, J.L., et al. (2011) Radiation Injury after a Nuclear Detonation: Medical Consequences and the Need for Scarce Resources Allocation. Disaster Medicine and Public Health Preparedness, 5, 532-544.

[129] Wang, Z., Chen, J.-Q., Liu, J.-L. and Qin, X.-G. (2016) Serious Neutropenia Following Neoadjuvant Chemotherapy for Locally Advanced Breast Cancer: A Case Report. Oncology Letters, 11, 1597-1599. https://doi.org/10.3892/ol.2016.4077

[130] Kasi, P.M., Tawbi, H.A., Oddis, C.V. and Kulkarni, H.S. (2012) Clinical Review: Serious Adverse Events Associated with the Use of Rituximab-A Critical Care Perspective. Critical Care, 16, 231. https://doi.org/10.1186/cc11304

[131] Saxena, N.S., Davis, K.L., Inlay, M.A., et al. (2016) High Resolution Mapping of Human Lymphopoiesis Reveals a Common Lymphoid Progenitor (CLP) Population. Blood, 128, 1473. http://www.bloodjournal.org/content/128/22/1473

[132] Ahmed, A.S.I., Sheng, M.H.C., Wasnik, S., Baylink, D.J. and Lau, K.-H.W. (2017) Effect of Aging on Stem Cells. World Journal of Experimental Medicine, 20, 1-10. https://doi.org/10.5493/wjem.v7.i1.1

[133] Das, R.K., Vernau, L., Grupp, S.A. and Barrett, D.M. (2019) Naive T Cell Deficits at Diagnosis and after Chemotherapy Impair Cell Therapy Potential in Pediatric Cancers. Cancer Discovery, 492-499. https://doi.org/10.1158/2159-8290.CD-18-1314

[134] Bracci, L., Schiavoni, G., Sistigu, A. and Belardelli, F. (2014) Immune-Based Mechanisms of Cytotoxic Chemotherapy: Implications for the Design of Novel and Rationale-Based Combined Treatments against Cancer. Cell Death and Differentiation, 21, 15-25. https://doi.org/10.1038/cdd.2013.67 
[135] Sakamoto, K. (2004) Radiobiological Bases for Cancer Therapy by Total or Half-Body Irradiation. Nonlinearity in Biology, Toxicology, Medicine, 2, 293-316. https://doi.org/10.1080/15401420490900254

[136] Scott, B.R. (2008) Low-Dose-Radiation Stimulated Natural Chemical and Biological Protection against Lung Cancer. Dose Response, 6, 299-318. https://doi.org/10.2203/dose-response.07-025.Scott

[137] Cuttler, J.M. (2013) Commentary on Fukushima and Beneficial Effects of Low Radiation. Dose Response, 11, 447-458. https://doi.org/10.2203/dose-response.13-008.Cuttler

[138] Kashcheev, V.V., Chekin, S.Y., Maksioutov, M.A., et al. (2015) Incidence and Mortality of Solid Cancer among Emergency Workers of the Chernobyl Accident: Assessment of Radiation Risks for the Follow-Up Period of 1992-2009. Radiation and Environmental Biophysics, 54, 13-23. https://doi.org/10.1007/s00411-014-0572-3

[139] Nair, R., Rajan, B., Akiba, S., et al. (2009) Background Radiation and Cancer Incidence in Kerala, India-Karanagappally Cohort Study. Health Physics, 96, 55-66. https://doi.org/10.1097/01.HP.0000327646.54923.11

[140] Chen, W.L., Luan, Y.C., Shieh, M.C., et al. (2007) Effects of Cobalt-60 Exposure on Health of Taiwan Residents Suggest New Approach Needed in Radiation Protection. Dose Response, 5, 63-75. https://doi.org/10.2203/dose-response.06-105.Chen

[141] Mortazavi, S.M.J. and Karam, P.A. (2013) Natural Radiation: High Background Radiation Areas (HBRAs) of Ramsar. Iran Research Gate, 5/9, 1-7. http://www.sums.ac.ir/ mmortazavi/ramsar.html 5/9/2013

[142] Oakley, P.A. (2015) Is Use of Radiation Hormesis the Missing Link to a Better Cancer Treatment? Journal of Cancer Therapy, 6, 601-605. https://doi.org/10.4236/jct.2015.67065

[143] Calabrese, E.J. and Mattson, M.P. (2017) How Does Hormesis Impact Biology, Toxicology, and Medicine? NPJ Aging and Mechanisms of Disease, 3, Article No. 13.

[144] Calabrese, E.J., Shamoun, D.Y. and Hanekamp, J.C. (2016) The Integration of LNT and Hormesis for Cancer Risk Assessment Optimizes Public Health Protection. Health Physics, 110, 256-259. https://doi.org/10.1097/HP.0000000000000382

[145] Calabrese, E. (2017) Mistake Led to Adopting the LNT Model in Toxicology, Says Calabrese. News \& Media Relations. https://www.umass.edu/newsoffice/article/mistake-led-adopting-lnt-model-toxicolo gy

[146] Robinson, A.B. (2013) Radiation Hormesis, Cancer, and Freedom in American Medicine. Journal of American Physicians and Surgeons, 18, 74-76. http://www.jpands.org/vol18no3/robinson.pdf

[147] Weber, W. and Zanzonico, P. (2017) The Controversial Linear No-Threshold Model. Journal of Nuclear Medicine, 58, 7-8. https://doi.org/10.2967/jnumed.116.182667

[148] Beyea, J. (2016) Response to, "On the Origins of the Linear No-Threshold (LNT) Dogma by Means of Untruths, Artful Dodges and Blind Faith.” Environmental Research, 148, 527-534. https://doi.org/10.1016/j.envres.2016.01.039

[149] Paganini, M. (2012) Linear No-Threshold Model. Physics H190, Spring Selected Lecture. https://documen.site/download/linear-no-threshold-model_pdf

[150] Mc Mahon, S.J., Schuemann, J., Paganetti, H. and Prise, K.M. (2016) Mechanistic Modelling of DNA Repair and Cellular Survival Following Radiation-Induced DNA Damage. Scientific Reports, 6, Article No. 33290. https://www.nature.com 
[151] Kakarougkas, A. and Jeggo, P.A. (2014) DNA DSB Repair Pathway Choice: An Orchestrated Handover Mechanism. The British Journal of Radiology, 87, 20130685. https://doi.org/10.1259/bjr.20130685

[152] Kostyrko, K. and Mermod, N. (2016) Assays for DNA Double-Strand Break Repair by Microhomology-Based End-Joining Repair Mechanisms. Nucleic Acids Research, 44, e56. https://doi.org/10.1093/nar/gkv1349

[153] Cuttler, J.M., Feinendegen, L.E. and Socol, Y. (2017) Evidence That Lifelong Low Dose Rates of Ionizing Radiation Increase Lifespan in Long- and Short-Lived Dogs. Dose Response, 15, Article ID: 155932581769290. https://doi.org/10.1177/1559325817692903

[154] Shoutko, A.N. and Ekimova, L.P. (2014) Abnormal Tissue Proliferation and Life Span Variability in Chronically Irradiated Dogs. Radiation and Environmental Biophysics, 53, 65-72. https://doi.org/10.1007/s00411-013-0504-7

[155] Shoutko, A.N. and Ekimova, L.P. (2017) The Effects of Tissue Regenerative Status on Hormesis in Dogs Irradiated during Their Lifespan. Open Journal of Biophysics, 7, 101-115. https://doi.org/10.4236/ojbiphy.2017.73009

[156] Xue, Q.-L. (2011) The Frailty Syndrome: Definition and Natural history. Clinics in Geriatric Medicine, 27, 1-15. https://doi.org/10.1016/j.cger.2010.08.009

[157] Shoutko, A. and Shatinina, N. (1998) Chronic Cancer-Could It Be? Coherence-International Journal of Integrated Medicine, 2, 36-40. http://www.iaam.nl/coherence/coherence0001.htm

[158] Shoutko, A. and Yurkova, L. (2001) Indirect Control of Tumor Growth in Radiotherapy. Coherence-International Journal of Integrated Medicine, 2, 36-40. http://www.iaam.nl/coherence/coherence0001.htm

[159] Shoutko, A.N., Ekimova, L.P., Vasilyeva, M.J. and Shatinina, N.N. (2000) Tissue Factors Involved in Cancer Induction. Proceedings of the 5 th International Conference on High Level of Natural Radiation and Radon Areas. Radiation Dose and Health Effects, Munich, 4-7 September 2000, 467-470.

[160] Janiak, M.K., Wincenciak, M., Cheda, A., Nowosielska, E.M. and Calabrese, E.J. (2017) Cancer Immunotherapy: How Low-Level Ionizing Radiation Can Play a Key Role. Cancer Immunology, Immunotherapy, 66, 819-832. https://doi.org/10.1007/s00262-017-1993-Z

[161] Fowler, J.F. (2010) 21 Years of Biologically Effective Dose. The British Journal of Radiology, 83, 554-568. https://doi.org/10.1259/bjr/31372149 